\title{
Development and sensory evaluation of potato (Solanum tuberosum) peel powder incorporated muffins for health
} \author{
Fatima $^{2}$, Mehak Naeem ${ }^{1}$ and Nishat Zafar ${ }^{3 *}$ \\ 1. Department of Nutrition and Dietetics, The University of Faisalabad, Punjab, Pakistan \\ 2. Department of Pathology, University of Agriculture, Faisalabad, Punjab, Pakistan \\ 3. Institute of Microbiology, University of Agriculture, Faisalabad, Punjab, Pakistan \\ *Corresponding author's email: nishat_zafar@yahoo.com
}

Anum Nazir ${ }^{1}$, Nizwa Itrat ${ }^{1}$, Uswa Ahmad ${ }^{1}$, Samina Allah Yar ${ }^{1}$, Kaneez

Citation

Anum Nazir, Nizwa Itrat, Uswa Ahmad, Samina Allah Yar, Kaneez Fatima, Mehak Naeem and Nishat Zafar. Development and sensory evaluation of potato (Solanum tuberosum) peel powder incorporated muffins for health. Pure and Applied Biology. Vol. 11, Issue 1, pp129-134. http://dx.doi.org/10.19045/bspab.2022.110014

\begin{tabular}{llll}
\hline \hline Received: 03/02/2021 & Revised: 23/04/2021 & Accepted: 03/05/2021 & Online First: 21/05/2021
\end{tabular}

\section{Abstract}

Adequate intake of dietary fiber is very beneficial for the prevention of chronic diseases. Hence, the present research was planned to determine the health-associated benefits of dietary fiber from potato peel. Nowadays, Obesity and diabetes are the most common diseases due to change in dietary patterns and changing lifestyles. These diseases can be cured by adding an adequate amount of dietary fiber to the diet and by physical activities. Potato peel which is the waste material of potato products contains about 50\% dietary fiber. Due to the strong nutritional profile of potato peel, it was used for the development of bakery products. Proximate analysis was done for the determination of the content of Moisture, Crude fat, Protein, Ash, Dietary fiber, and Nitrogen free extract (NFE). The present research was conducted to develop the potato peel powder incorporated muffins. Total four samples of muffins were prepared with the control group by using different concentrations of wheat flour and potato peel powder. The wheat flour was replaced by the potato peel powder according to the standard recipe of muffin at the different concentration levels 0,5 , 10 , and $15 \mathrm{~g} / 100 \mathrm{~g}$ of wheat flour. Sensory evaluation of muffins was done by panelists by using 9 points hedonic scale. The taste of all samples was acceptable; $\mathrm{T}_{3}$ had more dark color due to the high concentration of potato peel powder and overall acceptability observed in all samples. The results obtained by each parameter were observed statistically.

Keywords: Potato peel powder, Muffins preparation, proximate analysis, Sensory evaluation

\section{Introduction}

Obesity is characterized by the accumulation of fats in the body and increases the body weight beyond the desirable weight according to the personage, height, and bone structure [1]. In 2008, about 1.46 billion and 502 million adults are overweight and obese respectively [2]. The Pakistan National
Health Survey (NHS) documented that approximately $1 \%$ of the peoples are obese and 5\% are overweight at a young age (15-24 years) in Pakistan [3]. The health consequences of obesity are hypertension, diabetes mellitus, atherosclerosis, CVD, osteoarthritis, cholelithiasis, and coronary heart disease [4]. 
Diabetes is caused due to disturbance in the body metabolism and long term of diabetes cause many complications like lowering eyesight and failure of kidney and heart [5, 6]. Fiber affects the secretion of several hormones and Insoluble dietary fiber improves the markers of insulin resistance, helps in weight loss and immune function [7]. Potato peel is a waste material that contains a wide range of nutritionally and pharmacologically active components such as phenolic compounds, polysaccharides, and glycoalkaloids which are used as dietary fiber and natural anti-oxidant [8]. Glycoalkaloids are important bioactive compounds of potato and potato peel [9]. The potato peel is the best source of different beneficial functional ingredients in which include natural antioxidants, phenolic compounds, and fibers. Potato peel demonstrates the antihyper-glycemic effect, protects from cardiovascular diseases, decreases the level of cholesterol, and intestinal glucose absorption [10].

By focusing on all these facts present study was planned to develop a potato peel powder incorporated muffins for high fiber content and nutrient-dense. This innovative product is nutritious and reduces economic losses by using waste material.

\section{Materials and Methods}

This research was conducted in the Food and Nutrition Laboratory of the University of Faisalabad. This study was carried out in three phases i.e. chemical analysis of potato peel powder, product development, and sensory evolution of the product.

\section{Collection of material}

Potatoes were collected from the local market of Faisalabad.

\section{Procurement of raw material}

After the collection of potatoes, the sample was washed and removes foreign debris. Then potatoes were peeled manually. After peeling, the potato peel was dried in the already preheated oven to about $80^{\circ} \mathrm{C}$ and the temperature regulated to about $700^{\circ} \mathrm{C}$ for 10 hours until proper drying. The dry sample was ground and form powder by using a grinder and stored in the airtight polythene bag [11].

\section{Proximate analysis}

The potato peel powder was analyzed for their moisture content by using Air Forced Draft Oven, crude protein by using Kjeltech System, crude fat through Soxtet Apparatus by using n-hexane as a solvent, crude fiber through Labconco Fibertech, the total ash content in Muffle Furnace at $500 \pm 50^{\circ} \mathrm{C}$ and nitrogen-free extract (NFE\%) was measured by subtracting the values of moisture, fat, protein, ash and fiber from hundred according to their respective protocols mentioned in AOAC (2006) [12].

\section{Treatment protocol}

In the product development muffins with different levels of potato peel powder were prepared as shown in (Table 1) [13].

\section{Muffins preparation}

Muffins of different treatments as mentioned in the above table were prepared as shown in (Table 2) [14].

Table 1. Muffins with different levels of potato peel powder

\begin{tabular}{|c|c|c|}
\hline Treatment & Grams of potato peel powder & Grams of wheat flour \\
\hline T0 & 0 & 100 \\
\hline T1 & 5 & 90 \\
\hline T2 & 10 & 80 \\
\hline T3 & 15 & 70 \\
\hline
\end{tabular}


Table 2. Muffins recipe

\begin{tabular}{|c|c|}
\hline Ingredients & Quantity \\
\hline Wheat flour & $150 \mathrm{~g}$ \\
\hline Brown sugar & $100 \mathrm{~g}$ \\
\hline Milk & $100 \mathrm{ml}$ \\
\hline Eggs & 1 large \\
\hline Baking powder & $2 \mathrm{~g}$ \\
\hline Salt & $1 / 2 \mathrm{tsp}$ \\
\hline Olive oil & $150 \mathrm{ml}$ \\
\hline Vanilla essence & 2 drops \\
\hline Potato peel powder & Varied amount \\
\hline
\end{tabular}

\section{Preparation of muffins}

It was made by beating egg and brown sugar in a bowl with mixer and olive oil, milk, the essence was well mixed. Then in a separate bowl mix the wheat flour, potato peel powder as the amount required, baking powder, and salt. Measured this mixture $80 \mathrm{~g} 9$ times. For control, treatment made a mixture with same procedure except don't add potato peel powder. This mixture was measured as $80 \mathrm{~g} 3$ times. Placed this in a preheated oven at 200C for about 15 minutes. Then remove from oven and let cool before serving [15].

\section{Sensory evaluation}

Sensory evaluation of all the samples was done in terms of appearance, flavor, chewing ability, proofing, color, taste, texture, and overall acceptability by presenting prepared muffins to the panel of judges by using ninepoint Hedonic Scale described by Navarre et al. [16].

\section{Statistical analysis}

The data were subjected to statistical analysis and the level of significance was determined by using statistics [17]. The data collected were tabulated and then analyzed statistically through the Software "SPSS". The analysis of variance technique (one-way) ANOVA was applied to the results of proximate analysis and (one-way) ANOVA was applied to the results of sensory evaluation

\section{Results and Discussion}

The proximate composition of potato peels powder shown in (Table 3). Data in (Fig. 1) demonstrated the proximate constituents of potato peel powder. Moisture content (39.5g), crude protein $(9.6 \mathrm{~g})$, crude fat $(5.3 \mathrm{~g})$, dietary fiber $(7 \mathrm{~g})$, Ash content $(9.9 \mathrm{~g})$, and nitrogen-free extract $(27.6 \mathrm{~g})$ were recorded. In (Fig. 2), the graph showed the overall acceptability of the potato peel powder incorporated muffins:

Proximate analysis of potato peels powder The potato peel powder was analyzed for the proximate analysis and the result of proximate composition showed Moisture Content 43.3 \pm 6.21 , Dietary Fiber 7.1 \pm 0.10 , Crude Protein 9.8 \pm 0.20 , Crude Fat 5.4 \pm 0.10 , ASH Content 10.1 \pm 0.32 and NFE 27.7 \pm 0.15 . These results showed similarity to the study of Leo et al. [18].

\section{Sensory evaluation}

Sensory evaluation (appearance, flavor, chewability, proofing, adhesiveness, color, taste, texture, mouthfeel, and overall acceptability) is described in (Fig. 2) that shows the mean values in the range of color (6.80-7.80), appearance (7.00-7.60), flavor (6.60-7.60), proofing (6.80-7.80), softness (6.80-7.80), taste (6.80-7.80), chewability (7.20-7.80), texture (7.00-7.40), aroma (7.007.40) and overall acceptability (7.20-7.60). The color of $T_{3}$ is dark brown due to the gradually increasing concentration of potato peel powder.

According to Friedman et al., [19] study, change in color due to the brown color of potato peel and because the taste of dietary 
fiber has a bitter taste. That's why increasing the concentration of dietary fiber also gets a better taste of muffins. All the treatments were acceptable.

Table 3. Means values for proximate analysis of potato peel powder

\begin{tabular}{|c|c|}
\hline Proximate composition & Means \pm SD \\
\hline Moisture Content & $43.3 \pm 6.21$ \\
\hline Dietary Fiber & $7.1 \pm 0.10$ \\
\hline Crude Protein & $9.8 \pm 0.20$ \\
\hline ASH Content & $10.1 \pm 0.32$ \\
\hline Crude Fat & $5.4 \pm 0.10$ \\
\hline NFE & $27.7 \pm 0.15$ \\
\hline
\end{tabular}

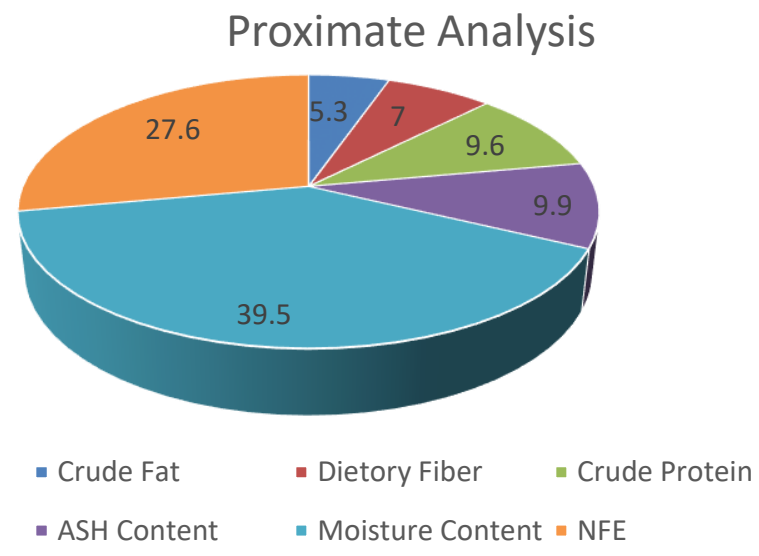

Figure 1. Proximate Composition of potato peel powder

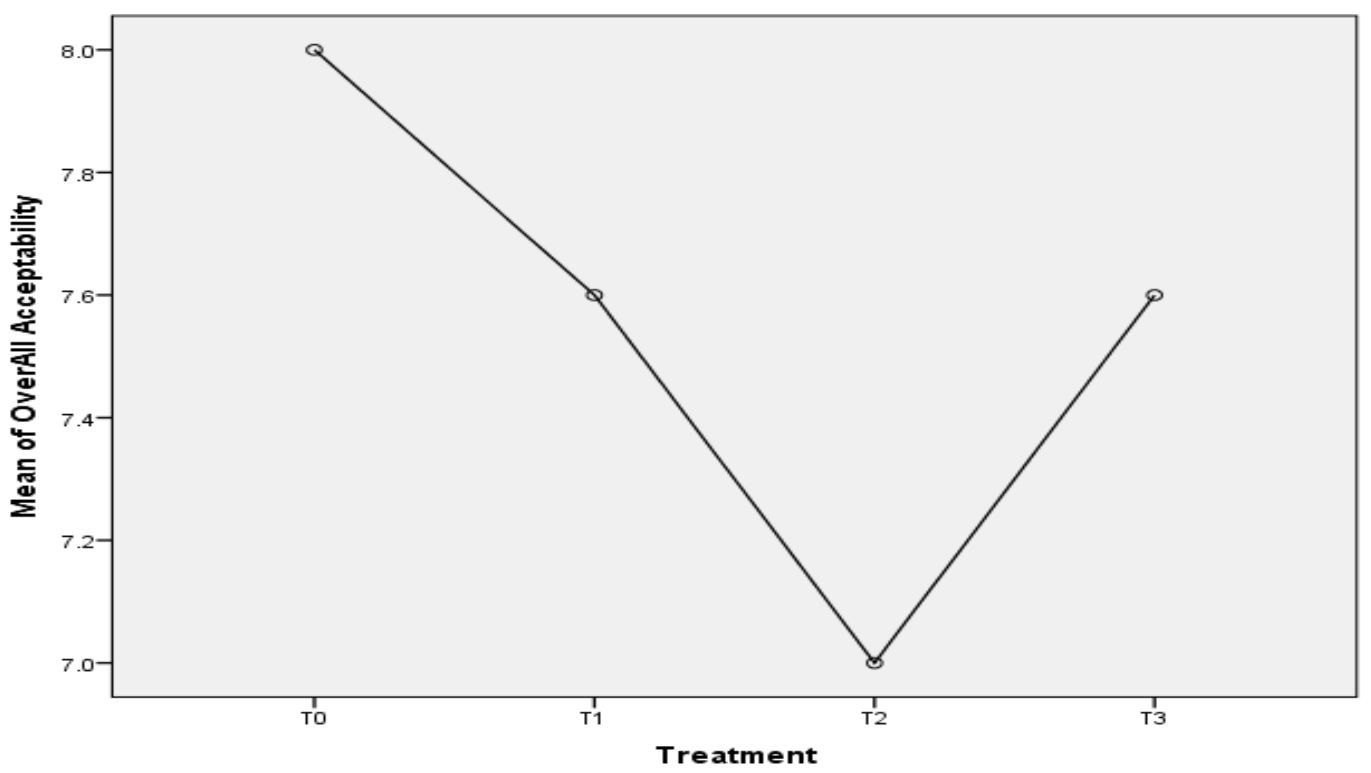

Figure 2. Means plot of overall acceptability for all treatments 


\section{Conclusion}

The present research revealed that potato peel had natural antioxidants and high nutrient content. Potato peel has an antihyperglycemic effect, protects from cardiovascular diseases, and decreases the level of cholesterol and intestinal glucose absorption. The chemical characterization of potato peel powders showed a high fiber and protein content. The inclusion at different concentrations of potato peel flour from the market (which the potato cultivar was not indicated) improved the nutritional, technological, and stability of formulated foodstuffs. After potato peel flour addition, the hardness of muffins was significantly ( $p$ $<0.05)$ decreased compared to the control muffin, the crumb color became darker were observed. These studies have shown the potential of developing fiber-rich muffins to increase dietary fiber intake. Potato peel incorporation in muffins showed the best results. All treatments are acceptable but $\mathrm{T}_{1}$ gains the highest score on the base of the 9point hedonic scale.

\section{Authors' contributions}

Conceived and designed the experiments: A Nazir, Performed the experiments: N Itrat \& U Ahmad, Analyzed the data: SA Yar, Contributed materials/ analysis/ tools: K Fatima \& M Naeem, Wrote the paper: N Zafar

\section{Reference}

1. Humayum A, Shah AS \& Sultana R (2009). Relation of hypertension with body mass index and age in male and female population of Peshawar, Pakistan. J Ayub Med Coll Abbottabad 21(3): 63-65.

2. Tanzil S \& Jamali T (2016). Obesity, an emerging epidemic in Pakistan-a review of evidence. J Ayub Med Coll Abbottabad 28(3): 597.

3. Aziz F, Ali MM \& Jabeen F (2017). Prevalence of overweight and obesity among young female students in association with BMI. RADS J Biolog Res \& Appl Sci 8(2): 01-04.

4. Khan MH, Khan H, Sarwar G \& Iftikhar B (2008). Study of obese persons profile at Di Khan, NWFP, Pakistan. Gomal J Med Sci 6(2).

5. Lattimer JM \& Haub MD (2010). Effects of dietary fiber and its components on metabolic health. Nut 2(12): 1266-1289.

6. Papathanasopoulos A \& Camilleri M (2010). Dietary fiber supplements: effects in obesity and metabolic syndrome and relationship to gastrointestinal functions. Gastroenterol 138(1): 65-72.

7. Weickert MO, \& Pfeiffer AF (2008). Metabolic effects of dietary fiber consumption and prevention of diabetes. The J Nut 138(3): 439-442.

8. Jeddou KB., Bouaziz F, Zouari-Ellouzi S, Chaari F, Ellouz-Chaabouni S, EllouzGhorbel R, \& Nouri-Ellouz O (2017). Improvement of texture and sensory properties of cakes by addition of potato peel powder with high level of dietary fiber and protein. Food Chem 217: 668677.

9. Camire ME, Kubow S, \& Donnelly DJ (2009). Potatoes and human health. Critical Rev food Sci Nut 49(10): 823-840.

10. Elhassaneen Y, Ragab R, \& Mashal R (2016). Improvement of bioactive compounds content and antioxidant properties in crackers with the incorporation of prickly pear and potato peels powder. Int J Nut Food Sci 5(1): 53.

11. Yangilar F (2013). The application of dietary fibre in food industry: structural Features, effects on health and definition, obtaining and analysis of dietary fibre: a review. J Food Nut Res 1(3): 13-23.

12. Vaitkevičienè N (2019). A comparative study on proximate and mineral composition of coloured potato peel and flesh. J Sci Food Agri 99(14): 62276233. 
13. Sepelev I \& Galoburda R (2015). Industrial potato peel waste application in food production: a review. Res Rural Devel 1: 130-136.

14. Joshi A, Sethi S, Arora B, Azizi AF, \& Thippeswamy B (2020). Potato Peel Composition and Utilization in potato. Springer, Singapore. pp. 229-245.

15. Schieber A, \& Saldaña MD (2009). Potato peels: a source of nutritionally and pharmacologically interesting compounds-a review. https://doi.org/10.7939/R33T9DM0H

16. Navarre DA, Goyer A \& Shakya R (2009). Nutritional value of potatoes: vitamin, phytonutrient, and mineral content. In Adv in Potato Chem and Technol pp. 395-424).
17. Pathak PD, Mandavgane SA, Puranik NM, Jambhulkar SJ, \& Kulkarni BD (2018). Valorization of potato peel: a biorefinery approach. Critical Rev Biotechnol 38(2): 218-230.

18. Leo L, Leone A, Longo C, Lombardi DA, Raimo F \& Zacheo G (2008). Antioxidant compounds and antioxidant activity in early potatoes. J Agri Food Chem 56(11): 4154-4163.

19. Friedman M, Kozukue N, Kim HJ, Choi SH \& Mizuno M (2017). Glycoalkaloid, phenolic, and flavonoid content and antioxidative activities of conventional nonorganic and organic potato peel powders from commercial gold, red, and Russet potatoes. J Food Compos Anal 62: 69-75. 